\title{
Baicalin attenuates lipopolysaccharide- induced neuroinflammation in cerebral cortex of mice via inhibiting nuclear factor kappa B (NF-kB) activation
}

\author{
Murad-Ali SHAH ${ }^{1) \#, ~ D o n g-J u ~ P A R K ~}{ }^{1) \#}$, Ju-Bin KANG ${ }^{1)}$, Myeong-Ok KIM ${ }^{2)}$ and \\ Phil-Ok KOH${ }^{1) *}$ \\ 1)Department of Anatomy, College of Veterinary Medicine, Research Institute of Life Science, Gyeongsang \\ National University, 501 Jinjudaero, Jinju, 52828, South Korea \\ ${ }^{2)}$ Division of Life Science and Applied Life Science, College of Natural Sciences, Gyeongsang National \\ University, 501 Jinjudaero, Jinju, 52828, South Korea
}

\section{J. Vet. Med. Sci.}

81(9): 1359-1367, 2019

doi: $10.1292 /$ jvms.19-0281

Received: 22 May 2019

Accepted: 22 July 2019

Advanced Epub: 1 August 2019
ABSTRACT. Baicalin is a plant-derived flavonoid that has anti-inflammatory and anti-oxidative effects. We investigated an anti-inflammatory effect of baicalin against lipopolysaccharide (LPS)-induced damage in cerebral cortex. Adult mice were divided into control, LPS-treated, and LPS and baicalin co-treated animals. LPS ( $250 \mu \mathrm{g} / \mathrm{kg} /$ day) and baicalin ( $10 \mathrm{mg} / \mathrm{kg} / \mathrm{day})$ were intraperitoneally injected for 7 days. LPS treatment induced histopathological changes in cerebral cortex, whereas baicalin protected neuronal cells against LPS toxicity. Moreover, baicalin treatment attenuated LPS-induced increases of reactive oxygen species and oxidative stress in cerebral cortices. Ionized calcium binding adaptor molecule-1 (lba-1) and glial fibrillary acidic protein (GFAP) are known as markers of activated microglia and astrocyte, respectively. Results of Western blot and immunofluorescence staining showed that LPS exposure induces increases of Iba-1 and GFAP expressions, whereas baicalin alleviates LPS-induced increases of these proteins. Baicalin also prevented LPS-induced increase of nuclear factor kappa B (NF-KB). LPS treatment led to increases of pro-inflammatory factors including interleukin-1 $\beta$ (IL-1 $\beta$ ) and tumor necrosis factor- $a($ TNF- $\alpha)$. Increases of these pro-inflammatory mediators were attenuated in baicalin co-treated animals. These results demonstrated that baicalin regulates neuroglia activation and modulates inflammatory factors in LPS-induced neuronal injury. Thus, our findings suggest that baicalin exerts a neuroinflammatory effect against LPS-induced toxicity through decreasing oxidative stress and inhibiting NF-KB mediated inflammatory factors, such as IL-1 $\beta$ and TNF- $\alpha$. KEY WORDS: baicalin, lipopolysaccharide, neuroinflammation, oxidative stress, reactive oxygen species

Inflammation is an important protective mechanism against injury or infection. It is a critical host defense response that regulated by specific mediators, such as cytokines and chemokines [3, 45]. Inflammation is considered as a primary response that characterized by excessive production of reactive oxygen species (ROS) [42]. Moreover, oxidative stress is a critical cause of neurodegenerative disorders [30]. Lipopolysaccharide (LPS) is an endotoxic component of gram-negative bacteria membrane [29]. LPS triggers microglia activation, releases inflammatory cytokines, increases ROS generation, and ultimately leads to inflammatory response $[26,28]$. It is well accepted that inflammatory cytokines and ROS are involved in neuroinflammation and neurodegeneration $[20,25,36]$.

Baicalin (7-glucuronic acid-5,6-dihydroxyflavone) is a plant-derived flavonoid that obtained from Scutellaria baicalensis Georgi and commonly used in Chinese medicine [16]. Baicalin has diverse health benefits, such as anti-inflammatory, anti-oxidative, and anti-apoptotic properties [15, 21, 46]. It also exerts anti-viral and anti-bacterial effects against infection [6, 24]. Moreover, baicalin inhibits LPS-induced inflammation and apoptosis in mammary epithelial cells by modulating nuclear factor-kappa B (NF- $\kappa$ B) and heat shock protein 72 [44]. It prevents exotoxin-stimulated macrophage activation and inhibits superantigen-induced inflammatory cytokines $[13,19]$. Furthermore, baicalin reduces LPS-evoked fever and tumor necrosis factor $\alpha($ TNF- $\alpha)$ expression $[8,40]$. Previous studies showed the anti-inflammatory and anti-apoptotic properties of baicalin in several organs including liver, lung

*Correspondence to: Koh, P.-O.: pokoh@gnu.ac.kr

\#These authors contributed equally to this work.

O2019 The Japanese Society of Veterinary Science

This is an open-access article distributed under the terms of the Creative Commons Attribution Non-Commercial No Derivatives (by-nc-nd) License. (CC-BY-NC-ND 4.0: https://creativecommons.org/licenses/by-nc-nd/4.o/) 
and kidney $[1,41]$. However, little information is reported about anti-neuroinflammatory effect of baicalin against LPS-induced neurotoxicity in cerebral cortex. Thus, this study is designed to elucidate the anti-neuroinflammatory mechanism of baicalin against LPS neurotoxicity in cerebral cortex of adult mice.

\section{MATERIALS AND METHODS}

\section{Experimental animals and drug treatment}

Male wild-type C57BL/6N mice ( 8 weeks, 31-33 g, $n=45$ ) were provided from Samtako Co. (Animal Breeding Centre, Osan, Korea). All experimental procedures were performed according to the guidelines of the Institutional Animal Care and Use Committee of Gyeongsang National University. Animals were housed at controlled lighting condition (12 hr light and $12 \mathrm{hr}$ dark) and temperature $\left(25^{\circ} \mathrm{C}\right)$. Feed and water were freely provided. Mice were randomly divided into three groups as follows: control group, LPS-treated group, and LPS and baicalin co-treated group. LPS ( $250 \mu \mathrm{g} / \mathrm{kg} / \mathrm{day}$, Sigma Aldrich, St. Louis, MO, U.S.A.) was dissolved in normal saline and baicalin $(10 \mathrm{mg} / \mathrm{kg} /$ day, Sigma Aldrich) was dissolved in $0.01 \%$ dimethyl sulfoxide with normal saline. Vehicle was used as a solvent solution without baicalin. Drugs were injected via intraperitoneal cavity for 7 days. Control group was administrated with vehicle. LPS-treated group was injected with only LPS and co-treated group was simultaneously injected with LPS and baicalin. Animals were euthanatized with Zoletil (50 mg/kg, Virbac, Carros, France) 1 day after last injection and body weights were measured. Brains tissues were carefully removed from skull.

\section{Reactive oxygen species (ROS) assay}

Cerebral cortices were homogenized in lysis buffer [1\% Triton X-100, 1 mM EDTA in PBS (pH 7.4)] and centrifuged at 15,000 $\mathrm{g}$ for $20 \mathrm{~min}$. After centrifuge, supernatants were collected and protein concentration was determined using bicinchoninic acid (BCA) protein analysis kit (Pierce, Waltham, MA, U.S.A.). Protein samples were diluted with cold Locke's buffer [154 mM NaCl, $5.6 \mathrm{mM} \mathrm{KCl}, 3.6 \mathrm{mM} \mathrm{NaHCO}, 2.0 \mathrm{mM} \mathrm{CaCl}_{2}, 10 \mathrm{mM}$ D-glucose, and $5 \mathrm{mM}$ 4-(2-hydroxyethyl)-1-piperazineethanesulfonic acid] at a concentration of $5 \mathrm{mg} / \mathrm{ml}$. Diluted protein samples were mixed with $5 \mathrm{mM} 2^{\prime}, 7^{\prime}$-dichlorodihydrofluorescein diacetate (DCFHDA, Sigma Aldrich) and incubated for $15 \mathrm{~min}$ at room temperature. The conversion of DCFH-DA to the fluorescent product 2'7'-dichlorofluorescein (DCF) was evaluated using a spectrofluorimeter with excitation at $484 \mathrm{~nm}$ and emission at $530 \mathrm{~nm}$. ROS analysis was expressed as DCF $\mathrm{pmol} / \mathrm{mg}$ of protein.

\section{Lipid peroxidation (LPO) assay}

LPO assay was performed for evaluation of oxidative stress through the measurement of LPO biomarker, malondialdehyde (MDA). LPO assay was carried out according to manufacturer's instruction (BioVision Inc., Milpitas, CA, U.S.A.). Cerebral cortices were homogenized in MDA lysis buffer with butylated hydroxytoluene and centrifuged at 13,000 g for $10 \mathrm{~min}$. After centrifuge, supernatants were collected and mixed with thiobarbituric acid. Sample mixtures were incubated for $1 \mathrm{hr}$ at $95^{\circ} \mathrm{C}$ and cooled for $10 \mathrm{~min}$. Absorbance of sample mixture was measured at $532 \mathrm{~nm}$ and MDA content was expressed as nmol/mg of protein.

\section{Hematoxylin and eosin staining}

Histopathological study was performed as a previously described routine method [12]. Briefly, brain tissues were fixed in $4 \%$ neutral buffered paraformaldehyde and washed with tap water for overnight. They were dehydrated in a graded series of ethyl alcohol (70 to 100\%), cleaned with xylene, and embedded in paraffin with routine protocol. Paraffin blocks were sectioned at a thickness of $4 \mu \mathrm{m}$ using a rotatory microtome (Leica, Wetzlar, Germany). Sections were mounted on slide glass and dried on slide warmer. They were immersed in xylene, rehydrated in a graded series of ethyl alcohol (100 to 70\%), and washed with water. Sections were stained with Harris hematoxylin solution (Sigma Aldrich) and eosin Y solution (Sigma Aldrich). After staining, sections were dehydrated with a graded ethyl alcohol series, cleaned in xylene, and subsequently mounted with mounting media (Thermo Fisher Scientific, Waltham, MA, U.S.A.). Mounted sections were observed with Olympus microscope (Olympus, Tokyo, Japan).

\section{Western blot analysis}

Cerebral cortices were immediately frozen and stored at $-70^{\circ} \mathrm{C}$. Western blot analysis was performed as a previously described manual [11]. Samples were homogenized in lysis buffer [1\% Triton X-100, 1 mM EDTA in PBS (pH 7.4)] and centrifuged at $15,000 \mathrm{~g}$ for $20 \mathrm{~min}$. Supernatants were collected and protein concentrations were measured with BCA protein assay kit (Pierce). Protein samples $(30 \mu \mathrm{g})$ were electrophoresed in 10\% sodium dodecyl sulfate poly-acrylamide gels and transferred to polyvinylidene fluoride membranes (Millipore, Billerica, MA, U.S.A.). Membranes were immersed in 5\% skim milk solution for 1 hr to block non-specific antibody bindings, washed with Tris-buffered saline containing $0.1 \%$ Tween-20 (TBST), and reacted with primary antibodies $(1: 1,000)$ overnight at $4^{\circ} \mathrm{C}$. Following primary antibodies were used; anti-ionized calcium binding adaptor molecule-1 (Iba-1), anti-glial fibrillary acidic protein (GFAP), anti-NF- $\kappa B$, anti-TNF- $\alpha$, anti-interleukin-1 $\beta$ (IL-1 $\beta$ ), and anti$\beta$-actin (Santa Cruz Biotechnology, Dallas, TX, U.S.A.). Membranes were washed with TBST and incubated with horseradish peroxidase-conjugated anti-rabbit IgG (1:5,000, Pierce). They were sequentially washed with TBST and reacted with enhanced chemiluminescense reagents (GE Healthcare, Chicago, IL, U.S.A.) for signals detection. Products were visualized on X-ray film (Fujifilm, Tokyo, Japan) and analyzed with Image J (National Institutes of Health, Bethesda, MD, U.S.A.). 


\section{Immunofluorescence staining}

Paraffin sections were deparaffinized in xylene and rehydrated in a graded ethyl alcohol series (100 to 70\%). Sections were washed with phosphate buffer saline (PBS) and incubated with normal goat serum for $1 \mathrm{hr}$ to block non-specific reaction. Sections were incubated with anti-Iba-1, anti-GFAP, anti-NF- $\kappa$ B, anti-TNF- $\alpha$, and anti-IL-1 $\beta$ (diluted 1:100, Santa Cruz Biotechnology) in a humidified chamber for overnight at $4^{\circ} \mathrm{C}$. They were washed with PBS and reacted with fluorescein isothiocyanate (FITC)conjugated secondary antibody (diluted 1:100; Santa Cruz Biotechnology) for 2 hr. They were reacted with 4',6-diamidino-2phenylindole (DAPI, Sigma Aldrich) for 10 min for counterstaining and mounted with Ultra-Cruz mounting medium (Santa Cruz Biotechnology). Positive reactions were observed with a confocal microscope (FV-1000, Olympus) and representative images were captured. Integrated intensities of positive signals were analyzed by Image-Pro Plus image software (Media Cybernetics, Rockville, MD, U.S.A.). Intensity values were expressed as a ratio of LPS-treated or baicalin co-treated group intensity to control group intensity. Intensity values of control group were set to 1 .

\section{Statistical analysis}

All results are presented as mean \pm standard error of mean (S.E.M.). The results of group were compared by two-way analysis of variance (ANOVA) followed by post-hoc Scheffe's test. A value of $P<0.05$ was considered statistically significant.

\section{RESULTS}

Figure 1A showed a significant decrease of body weight in LPS-treated animals. However, baicalin co-treatment alleviated LPSinduced decrease of body weight. Body weights were $32.0 \pm 1.61$ in LPS-treated and $36.7 \pm 1.75$ in baicalin co-treated animals. We measured ROS and MDA values to elucidate the effect of baicalin on LPS-induced oxidative stress in cerebral cortices. ROS and MDA levels were significantly increased in LPS-treated animals, these increases were attenuated in baicalin co-treated animals. ROS levels were $2.10 \pm 0.11$ and $1.50 \pm 0.05$ in only LPS-treated and baicalin co-treated animals, respectively (Fig. 1B). MDA levels were $2.61 \pm 0.12$ in LPS-treated and $1.63 \pm 0.05$ in baicalin co-treated animals (Fig. 1C). Results of hematoxylin and eosin staining showed serious histopathological changes in cerebral cortices of LPS-treated animals. Control animals had a typical pyramidal cell structure with well characterized round nuclei and dendrites (Fig. 1D and 1G). Neurons had a basophilic cytoplasm. Vacuole or lipid droplet was not observed in control animals. However, severe histological changes were observed in LPS-treated animals. LPS-treated animals had numerous vacuoles. Most of nerve cells had no processes of dendrite and surrounded by pericellular halos (Fig. 1D and 1F). These changes were observed in both neuron and neuroglia. Intact pyramidal cells with dendrites were not observed in these animals (Fig. 1E and 1H). These histopathological changes were alleviated in baicalin cotreated animals (Fig. 1F and 1I).

We observed the expressions of Iba-1 and GFAP as a marker for activated microglia and astrocyte, respectively. LPS treatment increased Iba-1 and GFAP expressions in the cerebral cortices, whereas baicalin co-treatment significantly prevented LPS-induced these increases (Fig. 2). Results of Western blot analysis showed that Iba-1 expression levels were $1.16 \pm 0.05$ in only LPS-treated animals and $0.66 \pm 0.04$ in baicalin co-treated animals (Fig. 2A and 2B). GFAP levels were $1.29 \pm 0.06$ and $0.82 \pm 0.05$ in LPStreated and baicalin co-treated animals, respectively (Fig. 2A and 2C). Moreover, data of immunofluorescence staining showed that Iba-1 and GFAP positive reactions increased in LPS-treated animals, these increases alleviated in baicalin co-treated animals (Fig. $2 \mathrm{D}$ and $2 \mathrm{E}$ ). Iba-1 and GFAP expressions values were evaluated as ratio of intensity of each group to intensity of control animals. Iba-1 expression values were $1.97 \pm 0.23$ in LPS-treated and $1.37 \pm 0.14$ in LPS and baicalin co-treated animals (Fig. 2F). GFAP values were $3.89 \pm 0.34$ and $2.13 \pm 0.24$ in LPS-treated and baicalin co-treated animals, respectively (Fig. 2G).

Figure 3 showed changes of NF- $\kappa \mathrm{B}$ expression in LPS-treated and baicalin co-treated animals. Baicalin treatment prevented LPS-induced increase in NF- $\kappa \mathrm{B}$ expression. NF- $\kappa \mathrm{B}$ expression levels were $1.51 \pm 0.06$ and $0.60 \pm 0.05$ in LPS-treated and baicalin co-treated animals, respectively (Fig. 3A and 3B). Results of immunofluorescence staining also showed that NF- $\kappa \mathrm{B}$ expression values were $1.48 \pm 0.10$ in LPS-treated and $1.13 \pm 0.15$ in baicalin co-treated animals (Fig. 3C and 3D). We elucidated changes of TNF- $\alpha$ and IL-1 $\beta$ expressions in LPS-treated and baicalin co-treated animals (Fig. 4). Western blot analysis showed that LPS treatment significantly increased TNF- $\alpha$ and IL- $1 \beta$ expressions in the cerebral cortices. However, baicalin treatment attenuated LPS-induced these increases. Results of Western blot analysis showed that IL- $1 \beta$ levels were $1.75 \pm 0.06$ and $0.47 \pm 0.04$ in LPStreated and baicalin co-treated animals, respectively (Fig. 4A and 4B). TNF- $\alpha$ levels were $1.53 \pm 0.06$ in LPS-treated and 0.78 \pm 0.05 in baicalin co-treated animals (Fig. 4A and 4C). We confirmed changes of these proteins using an immunofluorescence staining technique (Fig. 4D-F). IL-1 $\beta$ expression values were $2.38 \pm 0.31$ in LPS-treated and $1.48 \pm 0.19$ in baicalin co-treated animals (Fig. 4F). TNF- $\alpha$ expression values were $1.82 \pm 0.28$ and $1.32 \pm 0.27$ in LPS-treated and baicalin co-treated animals, respectively (Fig. 4G).

\section{DISCUSSION}

Baicalin exerts an anti-inflammatory effect in ischemic neuronal injury [17]. Moreover, baicalin has a less cytotoxicity and exerts superior anti-inflammatory and anti-oxidant effects to its aglycone form, baicalein [5]. This study explored an anti-inflammatory property of baicalin against LPS-induced inflammation in the cerebral cortex of adult mice. LPS administration activates the microglia and astrocyte. Activation of microglia leads to the releases of pro-inflammatory mediator and inflammatory cytokines, results in neuronal cell damage [7, 23]. Moreover, LPS-induced oxidative stress leads to the release of inflammatory cytokines, 

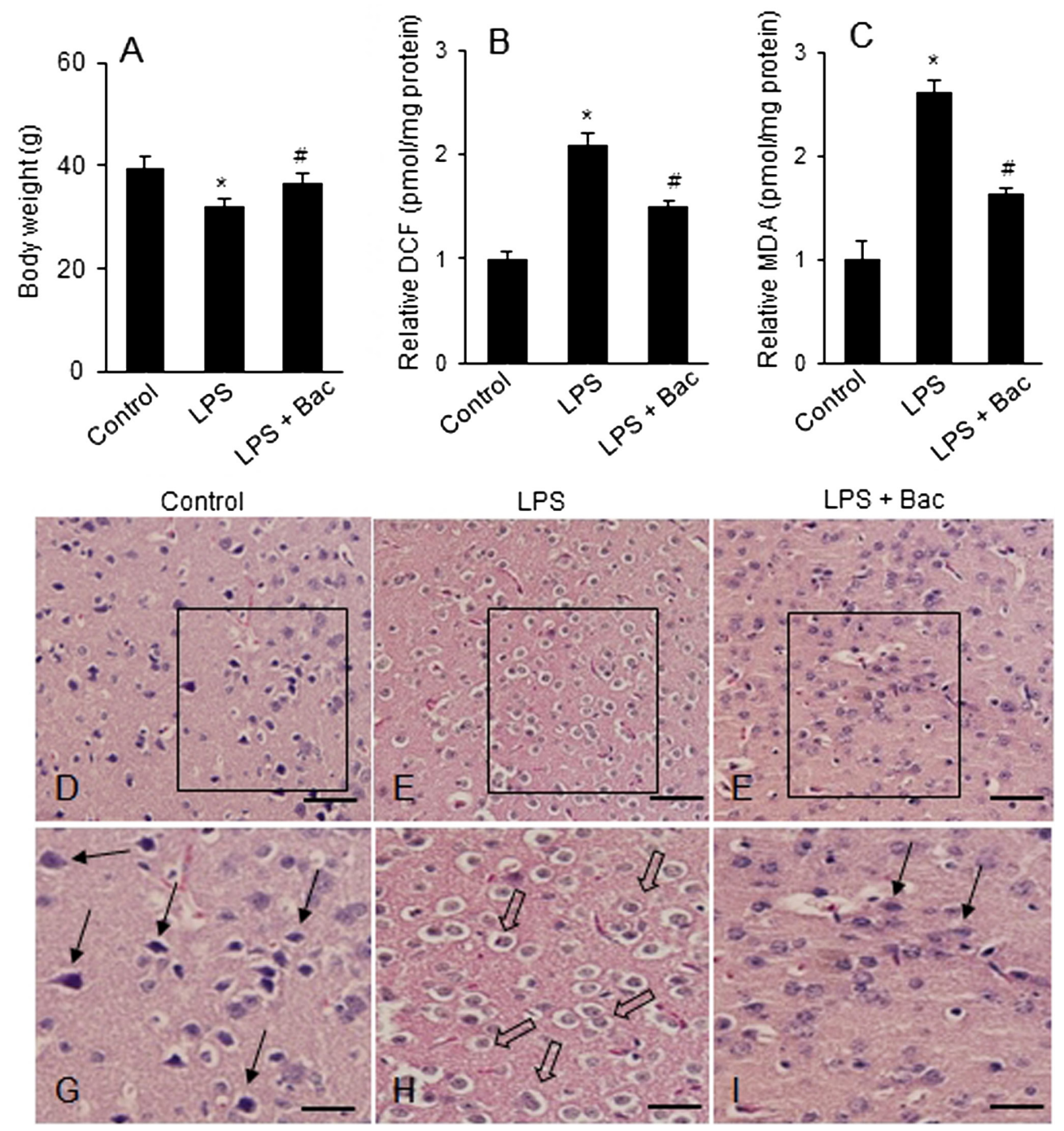

Fig. 1. Body weight (A), reactive oxygen species (ROS) (B), lipid peroxidation (C) analysis, and representative photos of hematoxylin and eosin staining (D-I) in cerebral cortices of control, lipopolysaccharide (LPS)-treated, and baicalin (Bac) co-treated animals. Baicalin attenuates LPSinduced decrease in body weight (A). LPS treatment increases ROS and MDA values, whereas baicalin attenuates these increases (B and C). LPS treatment induces histopathological changes, such as swelling and formation of vacuoles $(\mathrm{E}$ and $\mathrm{H})$. Baicalin alleviates these changes $(\mathrm{F}$ and I). Arrows indicate normal pyramidal cells (G and I) and open arrows indicate cells that have vacuoles and swelling pattern (H). Magnified photos indicate square region. Scale bar $=100 \mu \mathrm{m}(\mathrm{D}-\mathrm{F}), 200 \mu \mathrm{m}(\mathrm{G}-\mathrm{I})$. Data $(n=5)$ are shown as mean \pm S.E.M. $* P<0.05$ vs. control animal, $\# P<0.05$ vs. LPS-treated animal.

ROS, and nitric oxide [26, 28]. We showed that ROS and MDA levels are increased by LPS stimulation and baicalin mitigates LPS-induced these increases. We confirmed a significant decrease of body weight in LPS-treated animals. Baicalin treatment prevents this decrease. Moreover, baicalin attenuates LPS-induced the histopathological changes and preserves the structure of cortical neuron and neuroglia. These results demonstrated the fact that baicalin strongly reduces oxidative stress and neuronal cell damage against LPS neurotoxicity.

Baicalin inhibits macrophage activation caused by LPS toxicity and protects mice from endotoxic shock [19]. We showed that LPS induces activation of microglia and astrocyte in the cerebral cortex. Baicalin treatment alleviates LPS-induced activation of these cells. Iba-1 and GFAP were used as a marker for microglia and astrocyte activations. Iba-1 is an ionized calcium-binding adapter molecule which is mainly expressed in microglia [10]. It is an essential molecule in Rac signaling of activated microglia [9]. Up-regulation of Iba-1 supports dynamic features of microglia [9, 10]. This study showed that baicalin attenuates LPS-induced increase of Iba-1 expression in cerebral cortex. Increase of Iba-1 in LPS exposure demonstrates activation of microglia. Baicalin modulates Iba-1 expression during LPS toxicity-exposed neuronal damage. It is well known that GFAP is an intermediate filament protein which is expressed in astrocyte of the central nervous system. It maintains astrocyte mechanical strength and shape of cells, and involves with communication of cells and preformation of blood brain barrier. GFAP knockout mice showed degenerative processes, including abnormal myelination, structure deterioration, and blood-brain barrier impairment [18]. Moreover, 

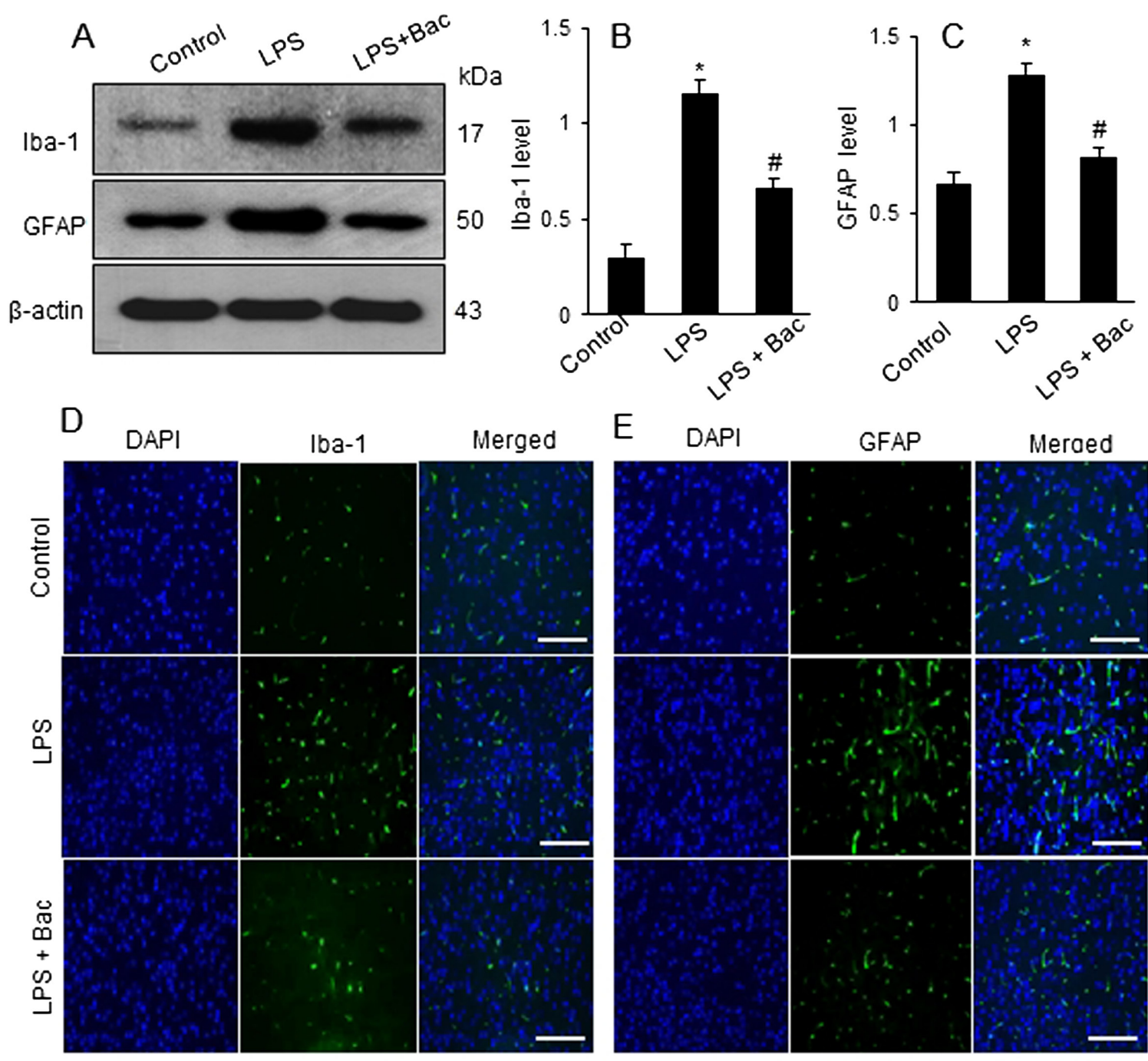

E DAPI
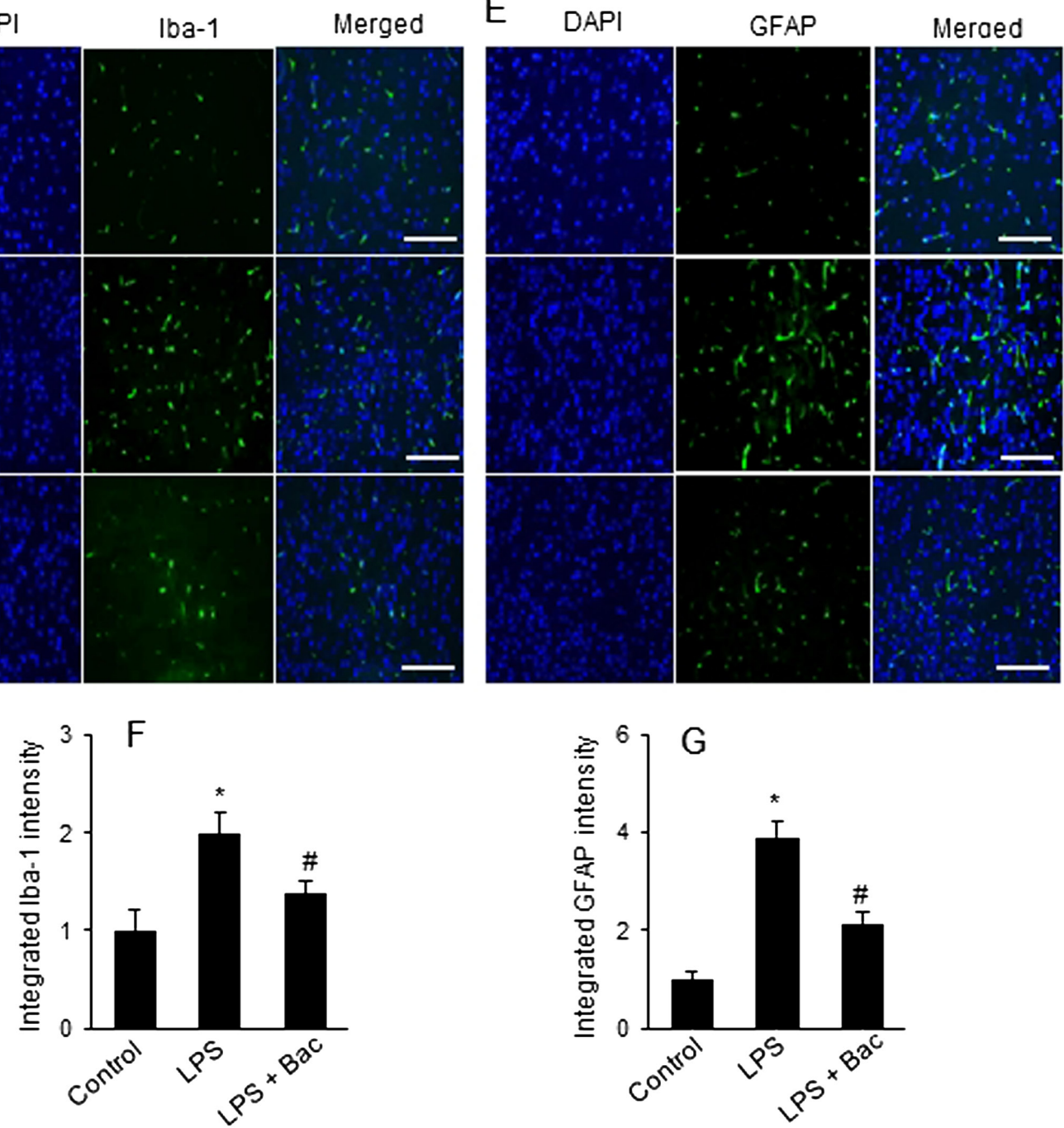

Fig. 2. Western blot analysis (A-C) and double immunofluorescence labeling (D-G) of ionized calcium binding adaptor molecule-1 (Iba-1) and glial fibrillary acidic protein (GFAP) in cerebral cortices of control, lipopolysaccharide (LPS)-treated, and baicalin (Bac) co-treated animals. Density values of Western blot analysis are expressed as a ratio of these proteins intensities to $\beta$-actin intensity. Intensity values of fluorescence were expressed as ratio of intensity of LPS-treated or baicalin co-treated animals to intensity of control animals. Data $(n=5)$ are shown as mean \pm S.E.M. Scale bar $=100 \mu \mathrm{m} . * P<0.05$ vs. control animal, $\# P<0.05$ vs. LPS-treated animal.

neurodegenerative conditions, such as trauma, infection, and auto-immune response increase the number of astrocytes and induce rapid synthesis of GFAP. GFAP plays essential roles in the central nervous system as markers of neural plasticity and activated astrocyte. Our results demonstrated that LPS leads to increase of GFAP value in cerebral cortex, whereas baicalin mitigates LPS-induced increase of GFAP. Increase of GFAP indicates over-activation of astrocytes during neurotoxic exposure. Thus, we 

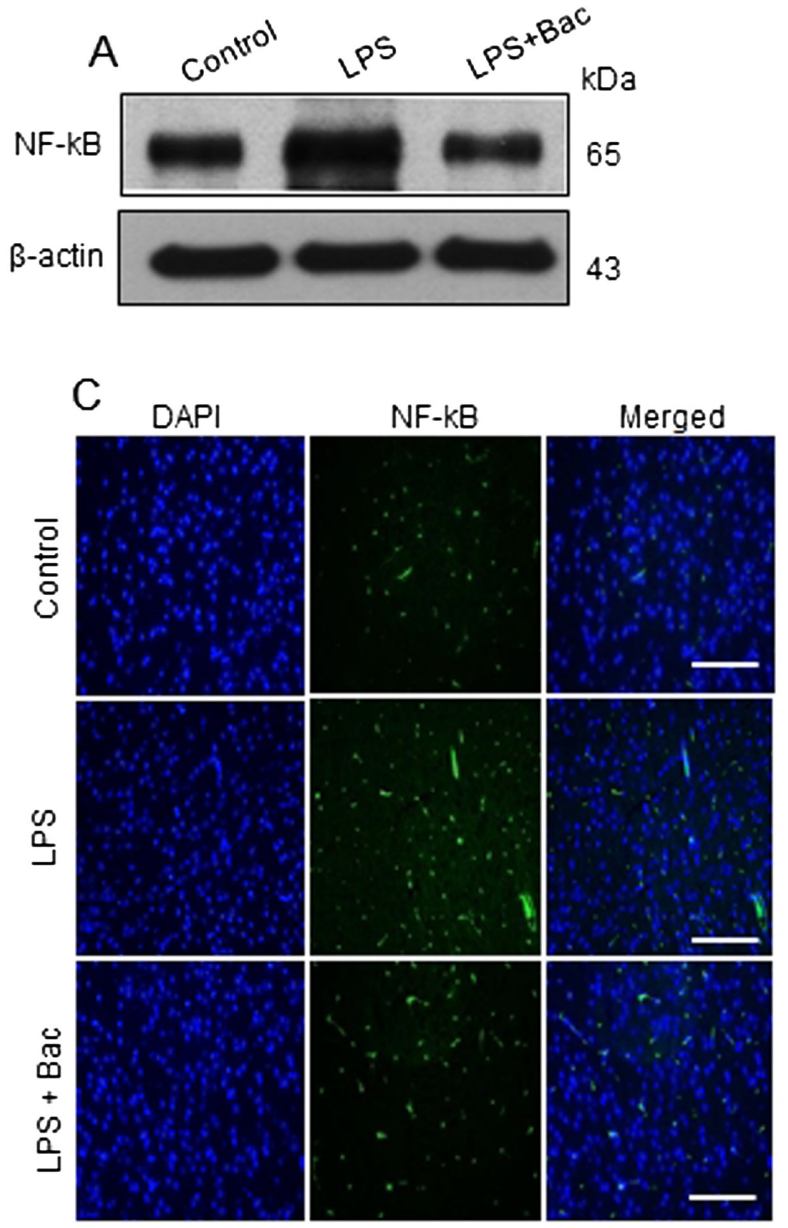

$\mathrm{B}$
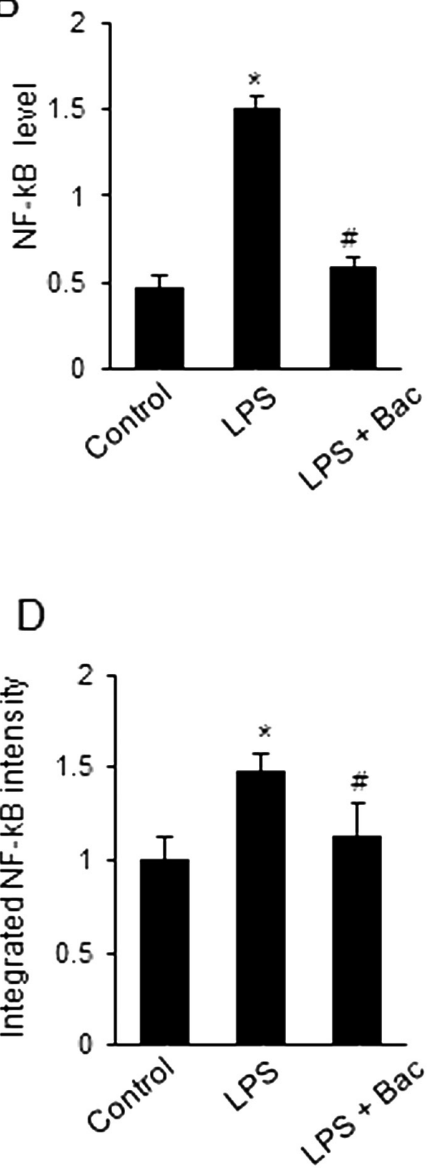

Fig. 3. Western blot analysis (A and B) and double immunofluorescence labeling (C and D) of nuclear factor kappa B (NF-kB) in cerebral cortex of control, lipopolysaccharide (LPS)-treated, and baicalin (Bac) co-treated animals. Density values of Western blot analysis are expressed as a ratio of NF- $\kappa$ B intensity to $\beta$-actin intensity. Intensity values of fluorescence were expressed as ratio of intensity of LPS-treated or baicalintreated animals to intensity of control animals. Scale bar $=100 \mu \mathrm{m}$. Data $(n=5)$ are shown as mean \pm S.E.M. $* P<0.05 \mathrm{vs.} \mathrm{control} \mathrm{animal,} \# P<0.05$ vs. LPS-treated animal.

can demonstrate that baicalin regulates Iba-1 and GFAP expressions in LPS-induced damage and contributes to modulation of microglia and astrocyte activations.

Inflammation is a defensive response against injurious stimuli and microbial infection. However, excessive inflammatory response causes serious tissue damage and systemic dysfunction, ultimately results in cell death. Pro-inflammatory cytokines are critical factors in the pathogenesis of inflammatory response. Macrophage plays a key role in inflammatory response through releasing pro-inflammatory cytokines, such as TNF- $\alpha$ and IL- $1 \beta$. NF- $\kappa$ B is a transcriptional factor that controls numerous genes expression associated with inflammation $[14,37]$. NF- $\kappa$ B performs a critical role in inflammatory responses, such as regulation of immune cell activation and differentiation of inflammatory $\mathrm{T}$ cells $[14,37]$. Moreover, NF- $\kappa \mathrm{B}$ is related to the pathogenesis of autoimmune diseases, such as rheumatoid arthritis and multiple sclerosis [27]. NF- $\kappa \mathrm{B}$ expression is also increased in neuroinflammatory response and oxidative stress [39]. Baicalin has an anti-inflammatory effect in osteoarthritis by reduce NF- $\kappa \mathrm{B}$ expression [4]. Moreover, baicalin alleviates inflammatory response caused by LPS through down-regulation of NF- $\mathrm{B}$ [44]. We showed that LPS toxicity induces increase of NF- $\kappa \mathrm{B}$ expression in cerebral cortex and baicalin attenuates LPS-induced this increase. Our results can demonstrate that baicalin alleviates LPS-induced inflammatory response through the regulation of NF- $\mathrm{KB}$ expression. NF- $\kappa B$ activates various inflammatory cytokines, such as IL- $1 \beta$ and TNF- $\alpha$ [14, 37]. IL- $1 \beta$ is a potent pro-inflammatory cytokine that stimulates CD4 T cells and promotes differentiation into the Thelper cells [33]. LPS treatment increases IL-1 $\beta$ expression in porcine alveolar macrophage [32]. IL-1 $\beta$ expression is also increased in LPS-induced cognitive impairment [38]. Our results showed that LPS treatment up-regulates IL-1 $\beta$ in cerebral cortex and baicalin attenuates this increase. We can demonstrate that baicalin reduces inflammation caused by LPS treatment through the regulation of IL-1 $\beta$ expression. Moreover, it is well known that TNF- $\alpha$ is an inflammatory cytokine that belongs to the superfamily of ligand proteins called tumor necrosis factor receptor [2]. TNF- $\alpha$ is secreted from macrophage and T helper lymphocyte in inflammatory response. TNF- $\alpha$ acts as a potent inflammatory mediator $[31,35]$. Previous study reported that TNF- $\alpha$ expression is increased in arthritis induced by LPS treatment 

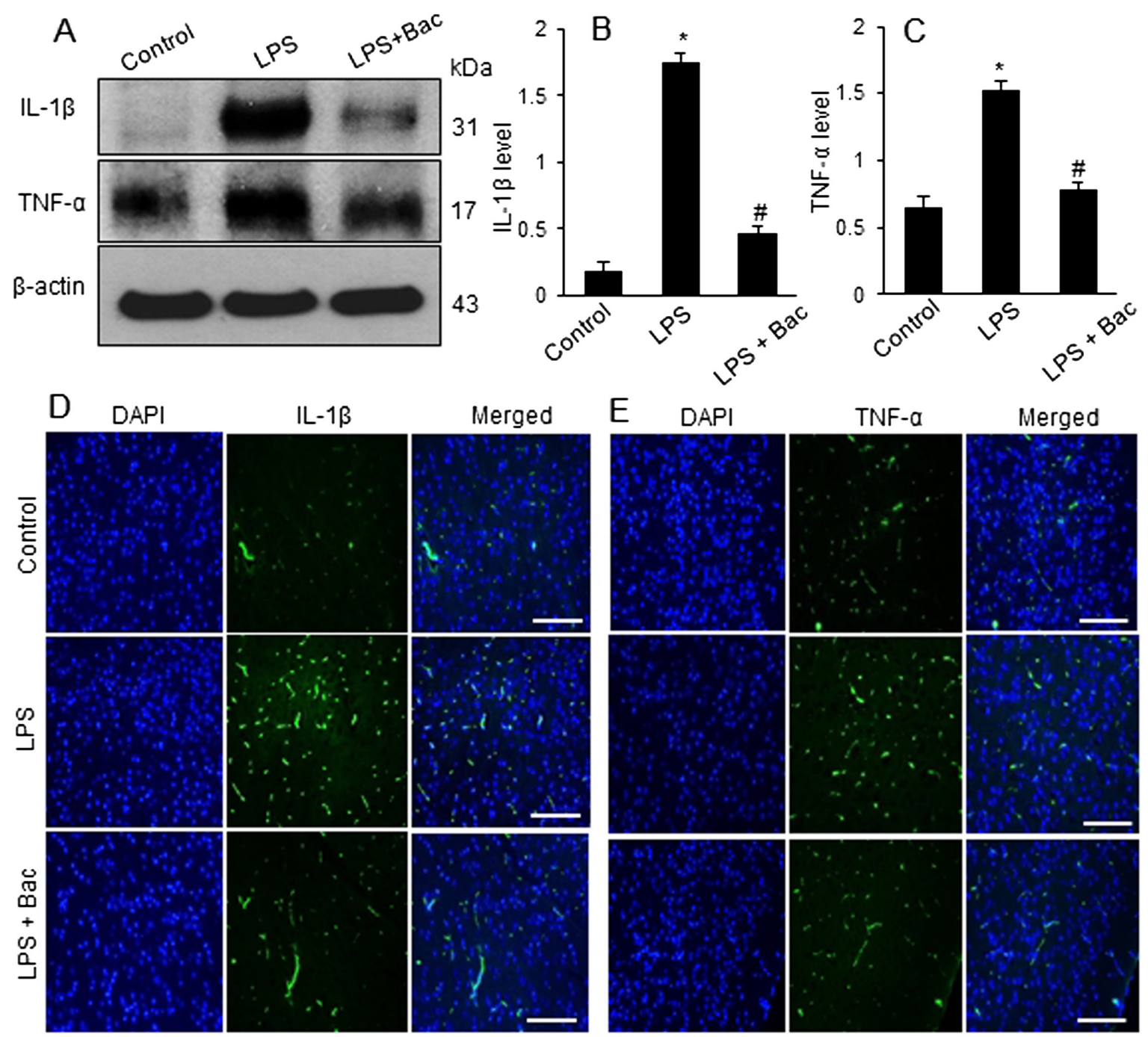

E DAPI

TNF- $a$

Merged
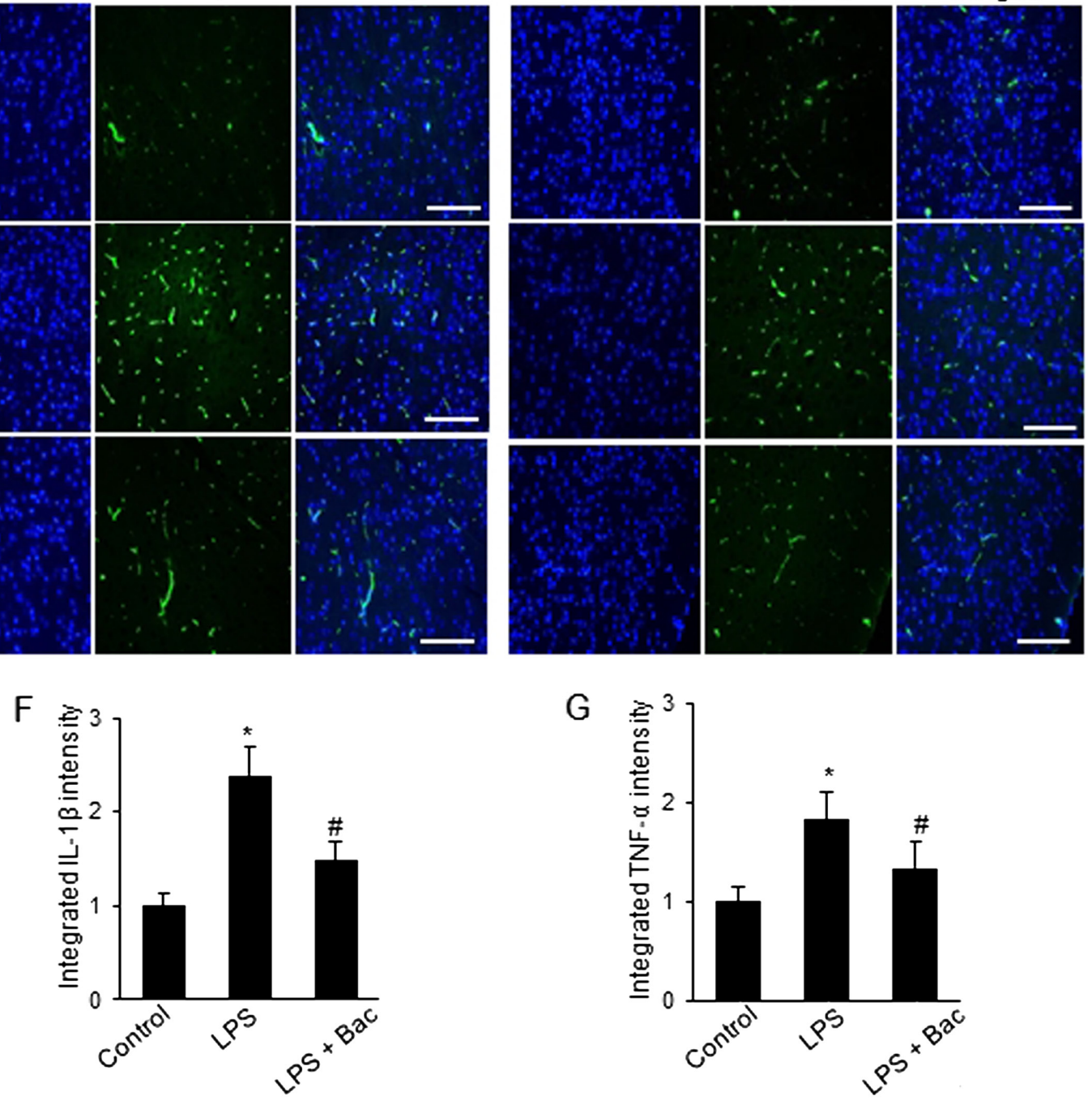

$\mathrm{G}$

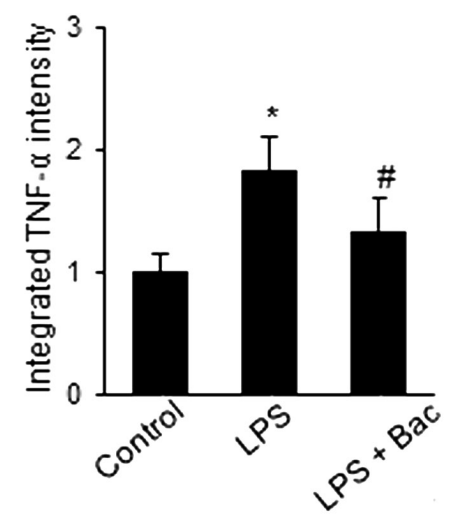

Fig. 4. Western blot analysis (A-C) and double immunofluorescence labeling (D-G) of interleukin-1 $\beta$ (IL-1 $\beta$ ) and tumor necrosis factor- $\alpha$ (TNF- $\alpha$ ) in cerebral cortices of control, lipopolysaccharide (LPS)-treated, and baicalin (Bac) co-treated animals. Density values of Western blot analysis are expressed as a ratio of these proteins intensity to $\beta$-actin intensity. Intensity values of fluorescence were expressed as ratio of intensity of LPS-treated or baicalin-treated animals to intensity of control animals. Scale bar $=100 \mu \mathrm{m}$. Data $(n=5)$ are shown as mean \pm S.E.M. $* P<0.05$ vs. control animal, $\# P<0.05$ vs. LPS-treated animal.

[22]. Moreover, TNF- $\alpha$ expression in cerebrum is increased by LPS-induced sepsis [34]. Previous study showed that baicalin suppresses TNF- $\alpha$ mRNA expression in acute pancreatitis [43]. This study showed that LPS induces increase of TNF- $\alpha$ expression in cerebral cortex, whereas baicalin alleviates LPS-induced up-regulation of TNF- $\alpha$. Thus, we can demonstrate that baicalin prevents LPS-induced inflammatory response via regulation of TNF- $\alpha$ expression. This study elucidated that baicalin exerts an 

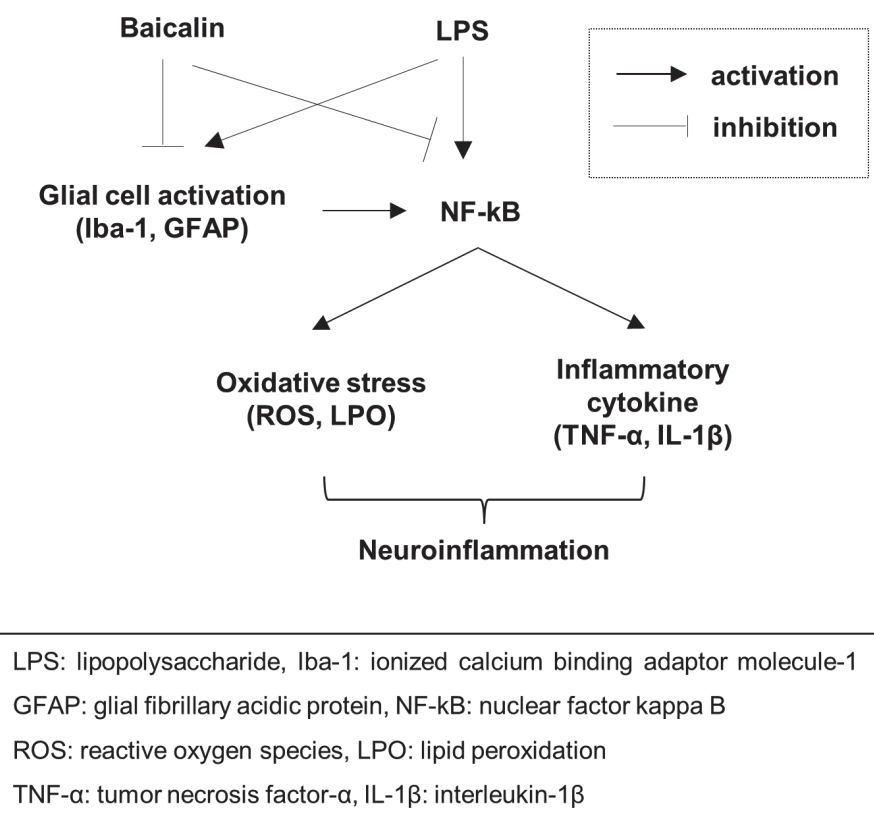

Fig. 5. Schematic diagram for protective effect of baicalin against lipopolysaccharide (LPS)-induced neuroinflammatory response.

anti-neuroinflammatory effect against LPS-induced inflammation in cerebral cortex. Baicalin mediates anti-inflammatory response through regulation of various inflammatory cytokines, including NF- $\kappa B$, IL- $1 \beta$, and TNF- $\alpha$. Therefore, our findings can suggest that baicalin contributes to neuroinflammatory response through prevention of neuroglial cells over-activation and regulation of inflammatory factors. In conclusion, baicalin attenuates LPS-induced inflammatory response in cerebral cortex of LPS-treated mice through decreasing oxidative stress and inhibiting NF- $\mathrm{BB}$ mediated inflammatory response. Figure 5 demonstrates schematic diagram for protective effects of baicalin against LPS-induced inflammatory response.

COMPETING FINANCIAL INTERESTS. The authors declare no competing financial interests.

ACKNOWLEDGMENT. This research was supported by the National Research Foundation of Korea (NRF) grant funded by the Korea government (MEST) (NRF-2018R1D1A1B07044074).

\section{REFERENCES}

1. Bai, C., Li, T., Sun, Q., Xin, Q., Xu, T., Yu, J., Wang, Y. and Wei, L. 2018. Protective effect of baicalin against severe burn-induced remote acute lung injury in rats. Mol. Med. Rep. 17: 2689-2694. [Medline]

2. Bodmer, J. L., Schneider, P. and Tschopp, J. 2002. The molecular architecture of the TNF superfamily. Trends Biochem. Sci. 27: 19-26. [Medline] [CrossRef]

3. Charo, I. F. and Ransohoff, R. M. 2006. The many roles of chemokines and chemokine receptors in inflammation. N. Engl. J. Med. 354: 610-621. [Medline] [CrossRef]

4. Chen, C., Zhang, C., Cai, L., Xie, H., Hu, W., Wang, T., Lu, D. and Chen, H. 2017. Baicalin suppresses IL-1ß-induced expression of inflammatory cytokines via blocking NF-kB in human osteoarthritis chondrocytes and shows protective effect in mice osteoarthritis models. Int. Immunopharmacol. 52: 218-226. [Medline] [CrossRef]

5. de Oliveira, M. R., Nabavi, S. F., Habtemariam, S., Erdogan Orhan, I., Daglia, M. and Nabavi, S. M. 2015. The effects of baicalein and baicalin on mitochondrial function and dynamics: A review. Pharmacol. Res. 100: 296-308. [Medline] [CrossRef]

6. Gao, X., Guo, M., Zhang, Z., Shen, P., Yang, Z. and Zhang, N. 2017. Baicalin promotes the bacteriostatic activity of lysozyme on S. aureus in mammary glands and neutrophilic granulocytes in mice. Oncotarget 8: 19894-19901. [Medline]

7. González-Scarano, F. and Baltuch, G. 1999. Microglia as mediators of inflammatory and degenerative diseases. Annu. Rev. Neurosci. 22: 219-240. [Medline] [CrossRef]

8. Huang, K. L., Chen, C. S., Hsu, C. W., Li, M. H., Chang, H., Tsai, S. H. and Chu, S. J. 2008. Therapeutic effects of baicalin on lipopolysaccharideinduced acute lung injury in rats. Am. J. Chin. Med. 36: 301-311. [Medline] [CrossRef]

9. Imai, Y. and Kohsaka, S. 2002. Intracellular signaling in M-CSF-induced microglia activation: role of Iba1. Glia 40: 164-174. [Medline] [CrossRef]

10. Ito, D., Imai, Y., Ohsawa, K., Nakajima, K., Fukuuchi, Y. and Kohsaka, S. 1998. Microglia-specific localisation of a novel calcium binding protein, Iba1. Brain Res. Mol. Brain Res. 57: 1-9. [Medline] [CrossRef]

11. Kang, J. B., Kim, D. K., Park, D. J., Shah, M. A., Kim, M. O., Jung, E. J., Lee, H. S. and Koh, P. O. 2018. Hyperglycemia aggravates decrease in alpha-synuclein expression in a middle cerebral artery occlusion model. Lab. Anim. Res. 34: 195-202. [Medline] [CrossRef]

12. Koh, P. O. 2017. Cerebral ischemic injury decreases $\alpha$-synuclein expression in brain tissue and glutamate-exposed HT22 cells. Lab. Anim. Res. 33: 
244-250. [Medline] [CrossRef]

13. Krakauer, T., Li, B. Q. and Young, H. A. 2001. The flavonoid baicalin inhibits superantigen-induced inflammatory cytokines and chemokines. FEBS Lett. 500: 52-55. [Medline] [CrossRef]

14. Lawrence, T. 2009. The nuclear factor NF-kappaB pathway in inflammation. Cold Spring Harb. Perspect. Biol. 1: a001651. [Medline] [CrossRef]

15. Li, B. Q., Fu, T., Gong, W. H., Dunlop, N., Kung, H., Yan, Y., Kang, J. and Wang, J. M. 2000. The flavonoid baicalin exhibits anti-inflammatory activity by binding to chemokines. Immunopharmacology 49: 295-306. [Medline] [CrossRef]

16. Li, H. B. and Chen, F. 2005. Isolation and purification of baicalein, wogonin and oroxylin A from the medicinal plant Scutellaria baicalensis by high-speed counter-current chromatography. J. Chromatogr. A 1074: 107-110. [Medline] [CrossRef]

17. Li, H. Y., Yuan, Z. Y., Wang, Y. G., Wan, H. J., Hu, J., Chai, Y. S., Lei, F., Xing, D. M. and Du, L. J. 2012. Role of baicalin in regulating Toll-like receptor 2/4 after ischemic neuronal injury. Chin. Med. J. (Engl.) 125: 1586-1593. [Medline]

18. Liedtke, W., Edelmann, W., Bieri, P. L., Chiu, F. C., Cowan, N. J., Kucherlapati, R. and Raine, C. S. 1996. GFAP is necessary for the integrity of CNS white matter architecture and long-term maintenance of myelination. Neuron 17: 607-615. [Medline] [CrossRef]

19. Liu, L. L., Gong, L. K., Wang, H., Xiao, Y., Wu, X. F., Zhang, Y. H., Xue, X., Qi, X. M. and Ren, J. 2008. Baicalin inhibits macrophage activation by lipopolysaccharide and protects mice from endotoxin shock. Biochem. Pharmacol. 75: 914-922. [Medline] [CrossRef]

20. Manton, K. G., Volovik, S. and Kulminski, A. 2004. ROS effects on neurodegeneration in Alzheimer's disease and related disorders: on environmental stresses of ionizing radiation. Curr. Alzheimer Res. 1: 277-293. [Medline] [CrossRef]

21. Martínez Medina, J. J., Naso, L. G., Pérez, A. L., Rizzi, A., Ferrer, E. G. and Williams, P. A. M. 2017. Antioxidant and anticancer effects and bioavailability studies of the flavonoid baicalin and its oxidovanadium(IV) complex. J. Inorg. Biochem. 166: 150-161. [Medline] [CrossRef]

22. Matsukawa, A., Yoshimura, T., Miyamoto, K., Ohkawara, S. and Yoshinaga, M. 1997. Analysis of the inflammatory cytokine network among TNF alpha, IL-1 beta, IL-1 receptor antagonist, and IL-8 in LPS-induced rabbit arthritis. Lab. Invest. 76: 629-638. [Medline]

23. Minghetti, L. and Levi, G. 1998. Microglia as effector cells in brain damage and repair: focus on prostanoids and nitric oxide. Prog. Neurobiol. 54: 99-125. [Medline] [CrossRef]

24. Moghaddam, E., Teoh, B. T., Sam, S. S., Lani, R., Hassandarvish, P., Chik, Z., Yueh, A., Abubakar, S. and Zandi, K. 2014. Baicalin, a metabolite of baicalein with antiviral activity against dengue virus. Sci. Rep. 4: 5452. [Medline] [CrossRef]

25. Na, K. S., Jung, H. Y. and Kim, Y. K. 2014. The role of pro-inflammatory cytokines in the neuroinflammation and neurogenesis of schizophrenia. Prog. Neuropsychopharmacol. Biol. Psychiatry 48: 277-286. [Medline] [CrossRef]

26. Nolan, Y., Vereker, E., Lynch, A. M. and Lynch, M. A. 2003. Evidence that lipopolysaccharide-induced cell death is mediated by accumulation of reactive oxygen species and activation of p38 in rat cortex and hippocampus. Exp. Neurol. 184: 794-804. [Medline] [CrossRef]

27. Pai, S. and Thomas, R. 2008. Immune deficiency or hyperactivity-Nf-kappab illuminates autoimmunity. J. Autoimmun. 31: 245-251. [Medline] [CrossRef]

28. Quan, N., Stern, E. L., Whiteside, M. B. and Herkenham, M. 1999. Induction of pro-inflammatory cytokine mRNAs in the brain after peripheral injection of subseptic doses of lipopolysaccharide in the rat. J. Neuroimmunol. 93: 72-80. [Medline] [CrossRef]

29. Raetz, C. R. H. and Whitfield, C. 2002. Lipopolysaccharide endotoxins. Annu. Rev. Biochem. 71: 635-700. [Medline] [CrossRef]

30. Reynolds, A., Laurie, C., Mosley, R. L. and Gendelman, H. E. 2007. Oxidative stress and the pathogenesis of neurodegenerative disorders. Int. Rev. Neurobiol. 82: 297-325. [Medline] [CrossRef]

31. Rothe, J., Gehr, G., Loetscher, H. and Lesslauer, W. 1992. Tumor necrosis factor receptors-structure and function. Immunol. Res. 11: 81-90. [Medline] [CrossRef]

32. Sacco, R. E., Nibbelink, S. K., Baarsch, M. J., Murtaugh, M. P. and Wannemuehler, M. J. 1996. Induction of interleukin (IL)-1beta and IL-8 mRNA expression in porcine macrophages by lipopolysaccharide from Serpulina hyodysenteriae. Infect. Immun. 64: 4369-4372. [Medline]

33. Santarlasci, V., Cosmi, L., Maggi, L., Liotta, F. and Annunziato, F. 2013. IL-1 and T helper immune responses. Front. Immunol. 4: 182. [Medline] [CrossRef]

34. Semmler, A., Hermann, S., Mormann, F., Weberpals, M., Paxian, S. A., Okulla, T., Schäfers, M., Kummer, M. P., Klockgether, T. and Heneka, M. T. 2008. Sepsis causes neuroinflammation and concomitant decrease of cerebral metabolism. J. Neuroinflammation 5: 38. [Medline] [CrossRef]

35. Smith, C. A., Farrah, T. and Goodwin, R. G. 1994. The TNF receptor superfamily of cellular and viral proteins: activation, costimulation, and death. Cell 76: 959-962. [Medline] [CrossRef]

36. Smith, J. A., Das, A., Ray, S. K. and Banik, N. L. 2012. Role of pro-inflammatory cytokines released from microglia in neurodegenerative diseases. Brain Res. Bull. 87: 10-20. [Medline] [CrossRef]

37. Tak, P. P. and Firestein, G. S. 2001. NF-kappaB: a key role in inflammatory diseases. J. Clin. Invest. 107: 7-11. [Medline] [CrossRef]

38. Terrando, N., Rei Fidalgo, A., Vizcaychipi, M., Cibelli, M., Ma, D., Monaco, C., Feldmann, M. and Maze, M. 2010. The impact of IL-1 modulation on the development of lipopolysaccharide-induced cognitive dysfunction. Crit. Care 14: R88. [Medline] [CrossRef]

39. Tóbon-Velasco, J. C., Cuevas, E. and Torres-Ramos, M. A. 2014. Receptor for AGEs (RAGE) as mediator of NF-kB pathway activation in neuroinflammation and oxidative stress. CNS Neurol. Disord. Drug Targets 13: 1615-1626. [Medline] [CrossRef]

40. Tsai, C. C., Lin, M. T., Wang, J. J., Liao, J. F. and Huang, W. T. 2006. The antipyretic effects of baicalin in lipopolysaccharide-evoked fever in rabbits. Neuropharmacology 51: 709-717. [Medline] [CrossRef]

41. Wang, Y., Jia, Y., Yang, X., Liang, B., Gao, H. and Yang, T. 2018. A potential role of Baicalin to inhibit apoptosis and protect against acute liver and kidney injury in rat preeclampsia model. Biomed. Pharmacother. 108: 1546-1552. [Medline] [CrossRef]

42. Waris, G. and Ahsan, H. 2006. Reactive oxygen species: role in the development of cancer and various chronic conditions. J. Carcinog. 5: 14. [Medline] [CrossRef]

43. Xiping, Z., Hua, T., Jie, Z., Li, C., Yang, C., Bei, L., Qijun, Y., Jing, Y., Wengqin, Y. and Ninnin, Z. 2009. Influence of baicalin on TNF-alpha mRNA, caspase-3 and P-selectin expression in pancreatic tissue of rats with severe acute pancreatitis. Indian J. Gastroenterol. 28: 131-135. [Medline] [CrossRef]

44. Yang, W., Li, H., Cong, X., Wang, X., Jiang, Z., Zhang, Q., Qi, X., Gao, S., Cao, R. and Tian, W. 2016. Baicalin attenuates lipopolysaccharide induced inflammation and apoptosis of cow mammary epithelial cells by regulating NF-кB and HSP72. Int. Immunopharmacol. 40: 139-145. [Medline] [CrossRef]

45. Zhang, J. M. and An, J. 2007. Cytokines, inflammation, and pain. Int. Anesthesiol. Clin. 45: 27-37. [Medline] [CrossRef]

46. Zheng, W. X., Wang, F., Cao, X. L., Pan, H. Y., Liu, X. Y., Hu, X. M. and Sun, Y. Y. 2014. Baicalin protects PC-12 cells from oxidative stress induced by hydrogen peroxide via anti-apoptotic effects. Brain Inj. 28: 227-234. [Medline] [CrossRef] 